\title{
BMJ Open Effect of warning symbols in combination with education on the frequency of erroneously crushing medication in nursing homes: an uncontrolled before and after study
}

\author{
Steven van Welie, ${ }^{1,2}$ Linda Wijma, ${ }^{2}$ Tim Beerden, ${ }^{2}$ Jasperien van Doormaal, ${ }^{2}$ \\ Katja Taxis ${ }^{1}$
}

To cite: van Welie $S$, Wijma L, Beerden T, et al. Effect of warning symbols in combination with education on the frequency of erroneously crushing medication in nursing homes: an uncontrolled before and after study. BMJ Open 2016;6: 012286.

doi:10.1136/bmjopen-2016012286

- Prepublication history and additional material is available. To view please visit the journal (http://dx.doi.org/ 10.1136/bmjopen-2016012286)

Received 14 April 2016 Revised 26 May 2016 Accepted 8 July 2016

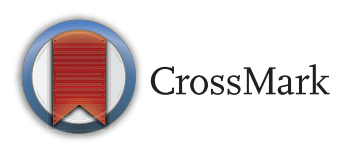

${ }^{1}$ Department of Pharmacy, Unit for Pharmacotherapy, Epidemiology \& Economics, University of Groningen, Groningen, The Netherlands ${ }^{2}$ Department of Clinical Pharmacy, Martini Ziekenhuis, Groningen, The Netherlands

Correspondence to Dr Katja Taxis; k.taxis@rug.nl

\section{ABSTRACT}

Objectives: Residents of nursing homes often have difficulty swallowing (dysphagia), which complicates the administration of solid oral dosage formulations. Erroneously crushing medication is common, but few interventions have been tested to improve medication safety. Therefore, we evaluated the effect of warning symbols in combination with education on the frequency of erroneously crushing medication in nursing homes.

Setting: This was a prospective uncontrolled intervention study with a preintervention and postintervention measurement. The study was conducted on 18 wards (total of 200 beds) in 3 nursing homes in the North of the Netherlands.

Participants: We observed 36 nurses/nursing assistants (92\% female; $92 \%$ nursing assistants) administering medication to 197 patients $(62.9 \%$ female; mean age 81.6).

Intervention: The intervention consisted of a set of warning symbols printed on each patient's unit dose packaging indicating whether or not a medication could be crushed as well as education of ward staff (lectures, newsletter and poster).

Primary outcome measure: The relative risk (RR) of a crushing error occurring in the postintervention period compared to the preintervention period. A crushing error was defined as the crushing of a medication considered unsuitable to be crushed based on standard reference sources. Data were collected using direct (disguised) observation of nurses during drug administration.

Results: The crushing error rate decreased from 3.1\% (21 wrongly crushed medicines out of 681 administrations) to $0.5 \%(3 / 636), \mathrm{RR}=0.15(95 \% \mathrm{Cl}$ 0.05 to 0.51 ). Likewise, there was a significant reduction using data from patients with swallowing difficulties only, $87.5 \%$ (21 errors/24 medications) to $30.0 \%(3 / 10)$ (RR $0.34,95 \% \mathrm{Cl} 0.13$ to 0.89 ). Medications which were erroneously crushed included enteric-coated formulations (eg, omeprazole), medication with regulated release systems (eg, Persantin; dipyridamol) and toxic substances (eg, finasteride).

\section{Strengths and limitations of this study}

- An innovative and feasible intervention consisting of warning symbols in combination with education reduced erroneous crushing of medication in nursing homes.

- Information on whether medication may be crushed was available at the stage of medication administration.

- The study design (an uncontrolled before and after study) means that we could not control for other factors potentially influencing the error rate.

Conclusions: Warning symbols combined with education reduced erroneous crushing of medication, a well-known and common problem in nursing homes.

\section{INTRODUCTION}

Nursing home residents often receive a large number of medicines. ${ }^{12}$ A considerable proportion of residents have difficulty swallowing (dysphagia), which complicates the administration of solid oral dosage formulations. ${ }^{3}$ Often, dose form modifications such as crushing tablets or opening capsules are done to administer medications. However, crushing formulations with special coatings or regulated release systems may result in subtherapeutic (crushing coatings) or toxic (crushing regulated-release systems) blood concentrations of the medicines causing adverse events. Furthermore, medications containing substances such as cytotoxic agents should not be crushed as small particles may harm the person handling the administration. ${ }^{4}{ }^{5}$ Recent studies in nursing homes suggest that between $0.5 \%$ and $10 \%$ 
of medications are erroneously crushed, ${ }^{4}{ }^{6-9}$ although this type of error seemed to be uncommon/absent in two other studies. ${ }^{10} 11$

Few studies have investigated interventions to reduce medication administration errors and most of these studies have been carried out in the hospital setting. ${ }^{12-14}$ Little is known about interventions to reduce the rate of erroneously crushing formulations in nursing homes. In a study in Dutch nursing homes, Stuijt $e t a l^{9}$ showed that a multifaceted intervention including education and a computerised system alerting staff to patients with swallowing difficulties was effective in reducing the frequency of wrongly crushed medication, but an error rate of about 3\% was still observed. In a study in Belgian nursing homes, an educational intervention including information on crushing of medication eliminated erroneous crushing. ${ }^{6}$ More research is needed to develop interventions to improve medication safety in the nursing home setting. Warning symbols in combination with education are widely used in healthcare to promote safety-appropriate behaviour. ${ }^{15}$ To the best of our knowledge, it has not been tested whether warning symbols can be used to reduce crushing errors. Therefore, we evaluated the effect of warning symbols in combination with education on the frequency of erroneously crushing medication in nursing homes.

\section{METHODS}

\section{Design and setting}

This was a prospective uncontrolled intervention study with a preintervention and postintervention measurement. The study was conducted on 18 wards (8-10 beds/ward, total of 200 beds) in three nursing homes in the north of the Netherlands. Patients were cared for by elderly care physicians, nurses, nursing assistants and volunteers. Electronic medical records and electronic prescribing systems were used in all institutions. Medication was supplied weekly by one hospital pharmacy as unit dose packages. Pharmaceutical services provided by pharmacists included daily computerised monitoring of all new prescriptions (eg, to detect drugdrug interactions) as well as regular multidisciplinary medication reviews of all patients. Nurses and nursing assistants were responsible to administer medication to residents. Administrations were recorded on the medication charts. In case patients had dysphagia and were prescribed medication they could not swallow, nurses contacted the prescriber or pharmacist to ask for a suitable alternative formulation (eg, liquid formulation) or nurses crushed medication.

The study was not reviewed by a medical ethics committee as, according to Dutch regulation, approval of the medical ethics committee was not required as there was no direct interaction with patients and patient data were anonymised (Dutch Medical Research Involving Human Subjects Act) ${ }^{16}$ Moreover, the intervention was part of an ongoing initiative for quality improvement and not put in place for the purpose of the study. Ward supervisors and management approved the study.

\section{Intervention}

The intervention consisted of the following four elements:

- Warning symbols printed on the unit dose sachets produced by the automatic tablet dispensing and packaging system. Two symbols were chosen, a positive symbol indicating that a tablet or capsule could be crushed and a negative symbol indicating that this could not be done. The symbols were added to the description line of each medication on the sachets (figure 1A, B). These were introduced on 1 February 2014. The information whether medication could be crushed or not was gathered by SvW, LW and TB based on standard reference sources. ${ }^{17} 18$ We chose a positive and a negative symbol to give nurses complete information including confirmation on which medication they were allowed to crush. In this way, we ensured that medication without a symbol (eg, medication where suitability of crushing had not been assessed yet) looked different. Technical limitations of the software of the unit dose dispensing system restricted the size and the choice of warning symbols which could be printed on the sachets. Pictograms in the form of pictures as developed by the Pharmacopeial Convention of the USA could not be used. ${ }^{19}$ We had to choose relatively simple symbols and could not add any colour.

- A 20 min lecture given by a pharmacist (LW or TB) to nurses and nursing assistants on each study ward in January and February 2014. It covered information on drug formulations which should not be crushed and informed staff on alternatives as well as explaining the introduction of the new symbols. Overall, 77 nurses and nursing assistants out of 160 (48\%) attended the lectures, about 4 per ward.

- A newsletter sent digitally to all nursing home staff in February 2014, summarising the content of the lecture on one page. This was a special edition of the quarterly newsletter of the hospital pharmacy. The newsletter was written by SvW, LW and TB.

- A poster explaining the meaning of the two symbols and emphasising that nursing staff should contact the physician or pharmacy department for patients with dysphagia who were prescribed medication which could not be crushed. The poster was introduced during the lectures. Nursing staff were advised to place the poster on the wards as a reminder. The poster was written by SvW, LW and TB.

We chose the three different educational approaches (lecture, newsletter and poster) to maximise the number of staff we could reach. Furthermore, these approaches were commonly used in our study setting (and also in other nursing homes), which increased the feasibility of the study and the applicability in other settings. 
A

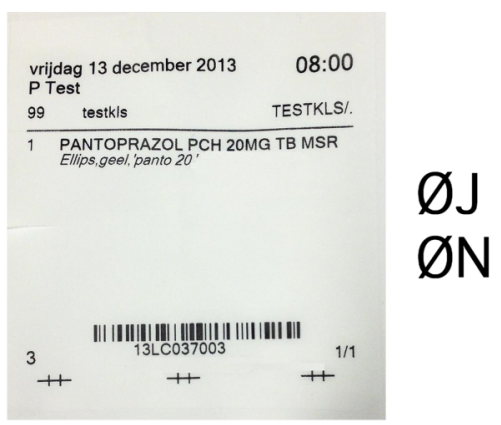

B

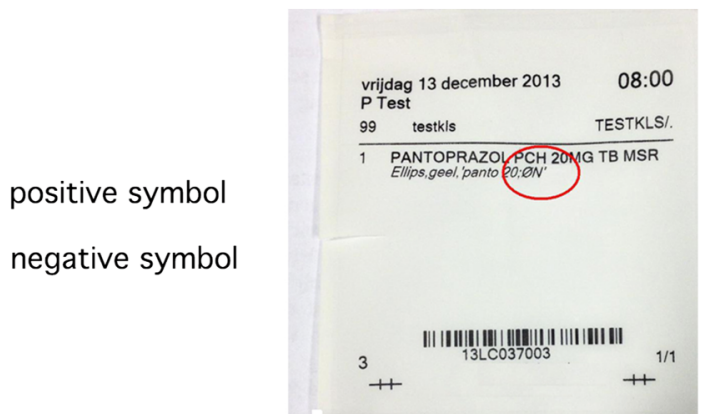

Figure 1 (A) An example of the unit dose sachet before introduction of the warning symbol. (B) Explanation of the two warning symbols. Positive symbol: formulation may be crushed ( $\mathrm{J}$ as short for ja=yes); negative symbol: formulation may not be crushed $(\mathrm{N}$ as short for nee=no); right: example of the unit dose sachet including the warning symbol.

\section{Data collection}

Data were collected using the disguised observation method, recognised as a valid and reliable method (gold standard) to detect medication administration errors $^{20}$ and suitable to be used to evaluate interventions. ${ }^{12}$ 21-23 In the current study, we have used the same approach as in our previous studies on medication administration errors, ${ }^{24}$ with essential elements comprising careful training of the observer and a consistent use of the definition of a crushing error. Ward staff were told that the observer was attending the medication rounds to get a general idea of the medication administration process as part of his hospital placement. Data were collected by one pharmacy student (author SvW), trained in observation technique including a 3-day test period on different wards. The observer asked each participating nurse/nursing assistant for permission to observe prior to the medication round. Sex and level of education (ie, qualified nurse or nursing assistant) were noted. He then accompanied staff during the medication rounds, observing all medication administrations to the patients. It was agreed that the observer should intervene in case he became aware of a potentially serious medication administration error, but this was not the case. The observer made a mental note of all medications which were crushed by nursing staff and recorded this information on paper immediately after leaving the ward.

After the drug round was completed, the observer retrieved data on observed patients and all medication administrations of oral solid dosage forms (ie, tablets and capsules) from the computerised pharmacy information system and entered this in Excel MS (Microsoft Corp., Redmond, Washington). Data comprised: name of the nursing home, type of ward, date and time of drug round, sex and age of the patient and medication details (number of medications administered during the observed drug round). For all medications which were crushed, full medication details (name and dose) were retrieved. SvW de-identified all patient information retrieved from the pharmacy information system.
Data were collected in November-December 2013 (preintervention period) and March 2014 (postintervention period). One medication round was observed on each ward in each period. The morning drug administration round (07:00-10:00) was selected as the majority of medications were administered during this round. Data collection was carried out on 18 consecutive weekdays each period, excluding weekends.

We defined a crushing error as the crushing of oral solid dosage forms considered unsuitable to be crushed according to Dutch standard references. We used two sources, a handbook by hospital pharmacists and the electronic database of the Royal Dutch Pharmaceutical Society. ${ }^{17}{ }^{18}$ Both sources are based on consensus of professionals. We chose the sources to ensure that we include cases which have been judged to be clinically relevant, that is, crushing potentially leading to changes in pharmacological response due to destroyed coating or regulated release systems or crushing of formulations containing toxic substances potentially harming staff handling the administration. The observer analysed the data and this was independently checked by two qualified pharmacists (TB and LW).

\section{Main outcome measure}

The main outcome was the relative risk (RR) of crushing errors in the postintervention compared to the preintervention period.

\section{Sample size}

On the basis of previous studies of crushing errors, ${ }^{4}{ }^{6-9}$ we assumed a rate of $3 \%$ wrongly crushed medication. Although using different interventions, previous studies showed considerable reductions in crushing error rates ${ }^{6}{ }^{9}$ so we expected to see a $66 \%$ reduction by the intervention. Overall, 500 medication administrations needed to be observed to be able to indicate a significant reduction $(\alpha=0.05$; power of 0.08$)$. It was estimated that 15 wards of about eight patients needed to be included. 


\section{Analysis}

Categorical data were compared by performing a $\chi^{2}$ test, while means were compared by performing Student's t-test. Data were analysed using SPSS V.20.0.0.2 (SPSS, Chicago, Illinois, USA). We calculated the percentage of erroneously crushing medication by dividing the number of crushing errors by the number of observed solid oral doses as has been done in previous studies. ${ }^{6914}$ We also calculated the error rate by dividing the number of crushing errors by the number of medications which should not have been crushed in patients with swallowing difficulties. We determined the RR and 95\% CI of erroneous crushing occurring after the intervention.

\section{RESULTS}

We observed 36 nurses/nursing assistants (92\% female; 92\% nursing assistants) administering medication to 197 patients (62.9\% female; mean age 81.6$)$. The groups of the preintervention and postintervention measurement were partly the same. There was no statistical difference between general characteristics of patients and the nursing staff of the preintervention and postintervention measurement (table 1).

We observed 681 medication administrations to 164 patients preintervention and 636 medication administrations to 150 patients postintervention. The number of patients who had their medication crushed decreased from $19(11.6 \%)$ to $11(7.3 \%)(p=0.20)$. These patients received 24 (preintervention period) and 10 (postintervention period) medications which should not be crushed.

We observed 21 crushing errors before and 3 crushing errors after the intervention. There was a significant decrease of erroneously crushing medication from $3.1 \%$ to $0.5 \%$ (RR 0.15 (95\% CI 0.05 to 0.51 ) using the denominator of all observed doses. Likewise, there was a significant reduction using data from patients with swallowing difficulties only, $87.5 \%$ (21 errors/24 medications) to
$30.0 \% \quad(3 / 10) \quad$ (RR $0.34, \quad 95 \%$ CI 0.13 to 0.89$)$. Medications which were erroneously crushed included enteric-coated formulations (eg, omeprazole), medication with regulated release systems (ie, Persantin; dipyridamol) and toxic substances (eg, finasteride). Erroneous crushing was observed on 11 out of the 18 wards $(61 \%)$ preintervention and 3 out of the 18 wards (17\%) postintervention. Error rates per ward can be found in online supplementary appendix 1 .

\section{DISCUSSION}

We observed a significant reduction in the rate of erroneously crushing medication after introducing warning symbols combined with education. The strength of our intervention was that information on crushing was available at the stage of administration at the point when nursing staff have to make a decision on how to give the medication to the patient. Technical limitations of the software of the unit dose dispensing system meant that we had to choose relatively simple symbols and could not add any colour. Our symbols could be improved by adapting one of the existing pharmaceutical pictograms which should be further tested to ensure comprehension. ${ }^{15}$ We gave lectures, distributed posters and sent a newsletter to combine the warning symbol with education to remind staff about inappropriate crushing and ensure comprehension of the symbols.

Within medication error research, an important choice is the way of calculating the medication error rate. ${ }^{20}{ }^{25}$ We calculated the crushing error rate by dividing the number of crushing errors by the total number of observed solid oral dosage forms. This is in line with previous studies on crushing errors ${ }^{6}{ }^{14}$ and studies on medication administration errors in general. ${ }^{20} 24 \mathrm{We}$ therefore chose this method to allow for comparison with the literature. In fact, our error rate was within the range of previous studies. An alternative way to calculate the error rate was to divide the number of crushing errors by the number of medications which should not

Table 1 Characteristics of participating nursing staff and patients

\begin{tabular}{|c|c|c|c|}
\hline & Preintervention & Postintervention & p Value \\
\hline Total number of nursing staff & 20 & 20 & \\
\hline Number of female nursing staff (percentage of all nursing staff) & $18(90)$ & $19(95)$ & $0.548^{*}$ \\
\hline Number of nursing assistants (percentage of all nursing staff) & $19(95)$ & $18(90)$ & $0.548^{*}$ \\
\hline Total number of patients & 164 & 150 & \\
\hline Number of female patients (percentage of all patients) & $106(64.6)$ & $99(66.0)$ & $0.800^{*}$ \\
\hline Mean age of patients & 81.7 & 81.5 & $0.893+$ \\
\hline Nursing home A-number of patients (percentage of all patients) & $40(24.4)$ & $37(24.7)$ & $0.667^{*}$ \\
\hline Nursing home B-number of patients (percentage of all patients) & $63(38.4)$ & $64(42.7)$ & \\
\hline Nursing home $\mathrm{C}$-number of patients (percentage of all patients) & $61(37.2)$ & $49(32.7)$ & \\
\hline $\begin{array}{l}\text { Mean number of observed oral solid medications per patient/observed } \\
\text { drug round }\end{array}$ & 4.15 & 4.24 & $0.761 \dagger$ \\
\hline
\end{tabular}


have been crushed in patients with swallowing difficulties. This also showed a significant decrease of the error rate supporting our conclusions. The second way of determining the error rate is less likely to be influenced by changes in medication use patterns.

We recommend wider implementation of the warning symbols in nursing homes. However, this depends on the use of unit dose dispensing systems and technical possibilities to add warning symbols on the sachets. Furthermore, it is important to have a service in place providing information on alternative medications for patients. An advantage is a good relationship between the pharmacy department and the nursing home staff like we have in our setting. ${ }^{26}$ Nurses were advised to contact the prescriber or the pharmacist to discuss alternatives (eg, liquid formulations) for patients with swallowing difficulties. Our computer system used for electronic prescribing also provided the possibility for physicians and nursing staff to document swallowing difficulties in the medication records. The pharmacist could then select alternative formulations before dispensing medication to the ward. Full implementation of documentation of dysphagia in the electronic records may be the next step in reducing crushing errors further. Stuijt $e t a t^{\ominus}$ have already shown that this is a successful strategy in reducing crushing errors.

Our study has several limitations. First, we used a before and after study design without including a control group. It was impossible to include a control group in our own setting as there was only one machine available to supply the unit doses. Technically, all wards had to receive the same unit doses (all with or without symbols). However, we are not aware of any changes taking place in the nursing homes during the intervention period which may have influenced the crushing error rate. Second, some limitations need to be discussed concerning the disguised observation technique. The presence of an observer may have an effect on behaviour of nursing staff, but this effect has been shown to be relatively limited. ${ }^{21}$ The observer was carefully trained in the observation technique. As a research group, we have ample experience with observation-based research. $^{22} 2327$ The observer took 'mental notes' of medication which had been crushed and recorded these instances straight after completing observation of each drug round. We chose this method, as taking notes during observation may be regarded as obtrusive and raise suspicion about the true nature of the study. There were only few doses which were crushed in each drug round, so it was easy to remember these instances correctly. All details of the administered medication were retrieved from the electronic-dispensing records available in the pharmacy department. Furthermore, it is important to note that the observer was not involved in any of the educational activities, so nursing staff were not aware of a link between the observer and the intervention. Unfortunately, we could not keep the observer blind. Being aware of the nature of the intervention theoretically could have introduced some bias in the data collection and analysis. However, since the definition of a crushing error was based on clear guidelines and assessment was independently checked and confirmed by two pharmacists, we think that this effect is negligible. Third, we did not assess the clinical significance of the observed errors. ${ }^{28}$ Anecdotal evidence would suggest that serious adverse events occur rarely, ${ }^{4}{ }^{29}$ so more research is needed to study the costeffectiveness of our intervention. A final limitation is that we investigated neither the contribution of each 'ingredient' of our intervention separately nor the longterm effect of our intervention. On the basis of theoretical grounds, we believe that a warning symbol should be accompanied by education to ensure comprehension. ${ }^{15}$ We did not assess the overall proportion of staff we reached with our educational activities. A reasonable number of staff attended the lectures (about 4 members of staff of each study ward, in total 77 out of 160 eligible members of staff, $48 \%$ ). It remains a challenge to distribute information effectively to all members including part time and temporary staff.

In our study, we used relatively traditional ways of disseminating the information on our innovation. Future studies could explore alternative approaches such as social media. Although we did not assess this as part of our trial, repeated educational efforts are probably necessary for a sustained effect. We also recommend to further develop easy to understand warning symbols/pictograms using colour, for example, red for not crushing, green for crushing using established guidelines. ${ }^{30}$ In summary, continuous education, improved symbols and the documentation of dysphagia problems in medical records may be a way to reduce the crushing error rate further. Finally, we hope to inspire others to use warning symbols or pictograms to improve patient safety following promising examples from patient education. ${ }^{31} 32$

\section{CONCLUSION}

Warning symbols combined with education reduced erroneous crushing of medication, a well-known and common problem in nursing homes. Wider implementation of this intervention could improve patient safety.

Acknowledgements The authors thank staff and patients from the participating nursing homes.

Contributors SvW collected the data, SvW and KT wrote the initial draft of the manuscript. All authors were involved in study design, analysis and interpretation of the data, and all authors revised the content and approved the final version of the manuscript.

Funding This research received no specific grant from any funding agency in the public, commercial or not-for-profit sectors.

Competing interests None declared.

Provenance and peer review Not commissioned; externally peer reviewed.

Data sharing statement No additional data are available.

Open Access This is an Open Access article distributed in accordance with the Creative Commons Attribution Non Commercial (CC BY-NC 4.0) license, 
which permits others to distribute, remix, adapt, build upon this work noncommercially, and license their derivative works on different terms, provided the original work is properly cited and the use is non-commercial. See: http:// creativecommons.org/licenses/by-nc/4.0/

\section{REFERENCES}

1. Onder $\mathrm{G}$, Liperoti R, Fialova $\mathrm{D}$, et al. Polypharmacy in nursing home in Europe: results from the SHELTER study. J Gerontol A Biol Sci Med Sci 2012;67:698-704

2. Taxis K, O'Sullivan D, Cullinan S, Drug utilization in older people. In: Elseviers M, Wettermark B, Almarsdóttir AB, et al. eds. Drug utilization research: methods and applications. London: Wiley-Blackwell, 2016:259-69.

3. Wright D. Medication administration in nursing homes. Nurs Stand 2002;16:33-8.

4. Stubbs J, Haw C, Dickens G. Dose form modification-a common but potentially hazardous practice. A literature review and study of medication administration to older psychiatric inpatients. Int Psychogeriatr 2008;20:616-27.

5. Crushing tablets or opening capsules: many uncertainties, some established dangers. Prescrire Int 2014;23:209-11, 213-14.

6. Verrue CL, Mehuys $\mathrm{E}$, Somers A, et al. Medication administration in nursing homes: pharmacists' contribution to error prevention. J Am Med Dir Assoc 2010;11:275-83.

7. van den Bemt PM, Idzinga JC, Robertz $\mathrm{H}$, et al. Medication administration errors in nursing homes using an automated medication dispensing system. J Am Med Inform Assoc 2009;16:486-92.

8. Haw C, Stubbs J, Dickens G. An observational study of medication administration errors in old-age psychiatric inpatients. Int J Qual Health Care 2007;19:210-16.

9. Stuijt CC, Klopotowska JE, Kluft-van Driel C, et al. Improving medication administration in nursing home residents with swallowing difficulties: sustainability of the effect of a multifaceted medication safety programme. Pharmacoepidemiol Drug Saf 2013;22:423-9.

10. Barker KN, Flynn EA, Pepper GA, et al. Medication errors observed in 36 health care facilities. Arch Intern Med 2002;162:1897-903.

11. Alldred DP, Standage C, Fletcher O, et al. The influence of formulation and medicine delivery system on medication administration errors in care homes for older people. BMJ Qual Saf 2011;20:397-401

12. Keers RN, Williams SD, Cooke J, et al. Impact of interventions designed to reduce medication administration errors in hospitals: a systematic review. Drug Saf 2014;37:317-32.

13. Berdot S, Roudot M, Schramm C, et al. Interventions to reduce nurses' medication administration errors in inpatient settings: a systematic review and meta-analysis. Int J Nurs Stud 2016;53:342-50.

14. Lohmann K, Gartner D, Kurze R, et al. More than just crushing: a prospective pre-post intervention study to reduce drug preparation errors in patients with feeding tubes. J Clin Pharm Ther 2015;40:220-5
15. Montagne M. Pharmaceutical pictograms: a model for development and testing for comprehension and utility. Res Social Adm Pharm 2013;9:609-20.

16. Central Committee on Research Involving Human Subjects. http:// www.ccmo.nl/en/your-research-does-it-fall-under-the-wmo (accessed 7 Jun 2015).

17. Bosma L, Boersma S, Heijenbrok T. [Handboek Enteralia, het toedienen van orale geneesmiddelen aan patiënten met een donse of slikklachten]. 2nd edn. Zwolle: Isala Klinieken, 2004.

18. Royal Dutch Association of Pharmacists (KNMP) Kennisbank, versie 2.1.9 (Dutch drug information database). https://kennisbank.knmp.nl/ (accessed 7 Jun 2015)

19. USP Pictograms. http://www.usp.org/usp-healthcare-professionals/ related-topics-resources/usp-pictograms (accessed 2 Aug 2016)

20. Taxis K. Administration of medication. In: Tully MP, Dean Franklin B, eds. Safety in medication use. 1st edn. CRC Press, 2015:35.

21. Dean B, Barber N. Validity and reliability of observational methods for studying medication administration errors. Am J Health Syst Pharm 2001;58:54-9.

22. Nguyen HT, Pham HT, Vo DK, et al. The effect of a clinical pharmacist-led training programme on intravenous medication errors: a controlled before and after study. BMJ Qual Saf 2014;23:319-24.

23. Chedoe I, Molendijk H, Hospes W, et al. The effect of a multifaceted educational intervention on medication preparation and administration errors in neonatal intensive care. Arch Dis Child Fetal Neonatal Ed 2012;97:F449-55.

24. Nguyen HT, Nguyen TD, van den Heuvel ER, et al. Medication Errors in Vietnamese Hospitals: Prevalence, Potential Outcome and Associated Factors. PLOS ONE 2015;10:e0138284.

25. Franklin BD, Taxis K, Barber N. Parenteral drug errors. Reported error rates are likely to be underestimation. BMJ 2009;338: b1814.

26. Wouters $\mathrm{H}$, Quik EH, Boersma F, et al. Discontinuing inappropriate medication in nursing home residents (DIM-NHR Study): protocol of a cluster randomised controlled trial. BMJ Open 2014;4 e006082.

27. Nguyen HT, Nguyen TD, Haaijer-Ruskamp FM, et al. Errors in preparation and administration of insulin in two urban Vietnamese hospitals: an observational study. Nurs Res 2014;63:68-72.

28. Taxis K, Dean B, Barber N. The validation of an existing method of scoring the severity of medication administration errors for use in Germany. Pharm World Sci 2002;24:236-9.

29. Kirkevold O, Engedal K. What is the matter with crushing pills and opening capsules? Int J Nurs Pract 2010;16:81-5.

30. Wogalter MS, Conzola VC, Smith-Jackson TL. Research-based guidelines for warning design and evaluation. Appl Ergon 2002;33:219-30.

31. Barros IM, Alcantara TS, Mesquita AR, et al. The use of pictograms in the health care: a literature review. Res Social Adm Pharm 2014;10:704-19.

32. Mok G, Vaillancourt R, Irwin D, et al. Design and validation of pictograms in a pediatric anaphylaxis action plan. Pediatr Allergy Immunol 2015;26:223-33. 